INPLASY

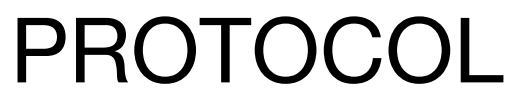

To cite: Fahmy et al. Impact of the prostate size on the outcome of radical prostatectomy. Inplasy protocol 2021110035. doi: 10.37766/inplasy2021.11.0035

Received: 11 November 2021

Published: 11 November 2021

Corresponding author: Omar Fahmy

omarfahmy.ahmed@upm.edu.my

Author Affiliation:

King Abdulaziz University.

Support: Research grant.

Review Stage at time of this submission: Data analysis Completed but not published.

Conflicts of interest:

None declared.

\section{Impact of the prostate size on the outcome of radical prostatectomy}

Fahmy, O1; Fahmy, UA2; Abdelhahim, O3; Khairul-Asri, MG4.

Review question / Objective: What is the impact of prostate size on the outcome of radical prostatectomy.

Eligibility criteria: Studies reported on the impact of the prostate size on the outcome of radical prostatectomy.

Main outcome(s): operative time, blood loss, complications, incontinence, positive surgical margins, biochemical recurrence.

INPLASY registration number: This protocol was registered with the International Platform of Registered Systematic Review and Meta-Analysis Protocols (INPLASY) on 11 November 2021 and was last updated on 11 November 2021 (registration number INPLASY2021110035).

\section{INTRODUCTION}

Review question / Objective: What is the impact of prostate size on the outcome of radical prostatectomy.

Condition being studied: Surgical, functional and oncological outcomes.

METHODS

Participant or population: 12242 patients.
Intervention: Radical prostatectomy.

Comparator: Small versus large prostate.

Study designs to be included: Controlled studies.

Eligibility criteria: Studies reported on the impact of the prostate size on the outcome of radical prostatectomy.

Information sources: Electric databases. 
Main outcome(s): Operative time, blood loss, complications, incontinence, positive surgical margins, biochemical recurrence

Quality assessment / Risk of bias analysis: NOS.

Strategy of data synthesis: Comparison between small and large prostate patients.

Subgroup analysis: Small versus large prostate.

Sensitivity analysis: Using Revman5. 4 software.

Country(ies) involved: Malaysia, Saudi Arabia.

Keywords: Prostate size, Prostate volume, radical prostatectomy, Prostate cancer.

Contributions of each author:

Author 1 - Omar Fahmy.

Author 2 - Usama Ahmed.

Author 3 - Osama Abdelhakim.

Author 4 - Mohd Ghani Khairul-Asri. 